\title{
En man mitt i den svenska stormakttidens utkant - Petter Rudebeck och hans annorlunda historia
}

\section{Av Håkan Nordmark, doktorand i historia}

\author{
Länk till presentation av Håkan Nordmark
}

Under slutet av 1600-talet låg den kända staden Troja i Småland, närmare bestämt i Almundsryds socken som gränsar till till Skåne. Den som hade anlagt staden var ingen mindre än den driftige Oden, som förresten inte alls var någon gud utan en människa av kött och blod. Man kan också få höra den meningen att Oden hade bott och verkat som kung i Småland på en gård som kom att kallas Asgård i en socken som efter honom, den främste bland asar kom att kallas just Asa. I och med sin trollkunnighet blev denne duktige och mångkunnige man betraktad som en gud av folket. Tycker någon att namnet Troja inte låter särskilt småländskt eller ens svenskt bör man tänka på att staden har fătt sitt namn av de starka vallar och befästningsmurar som omgav den som skydd, precis som kroppen omges och skyddas av en tröja!

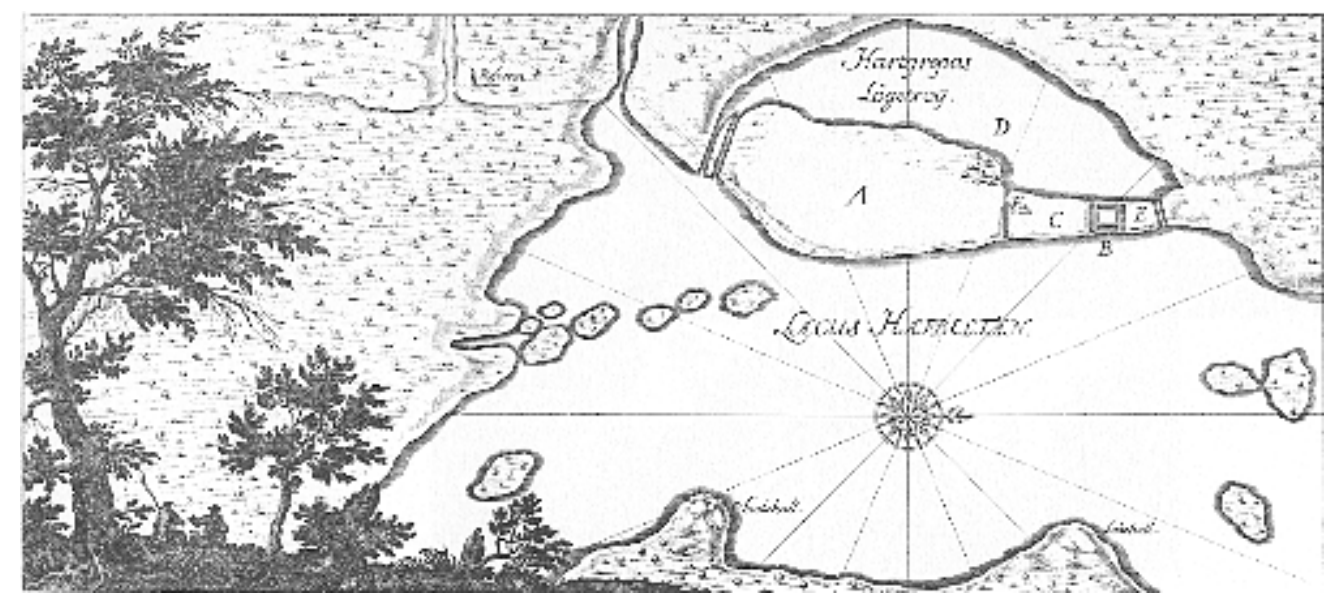

Ill. 1. Karta över staden Troja i Småland ur Erik Dahlbergs Svecia Antiqua et Hodierna.

Rubriken till kopparsticket talar om för oss att kartan föreställer "Den af hedenhöös uråldrige staden Troja, som uti Odens tid, efter hans ankomst utur Asien är vorden funderat" Förklaraingarna till bokstäverna i bilden är följande: "A. Själva gamla staden Troja, nuförtiden alldeles devasterat och öde. B. Trojenborg eller det gamla Allfaders residens och säte. C. Hovgården där De Tolv Domare bodde. D. Gunnil Grepas eller Hartgrepa lögetrog, varuti hon lögade sina barn, vilkets vatten ännu är rödaktigt, som säges av det myckna blod som vid Trojas erövrande är utgjutet. E. En åker som ännu i dena dag finnes full med människoben. F. En våning där oden lät sig synas varje afton, enär någon hjältegrav vart mot hans vilja opärder" På detta kopparstick, som tillkommit på Petter Rudebecks initiativ, ses även en "Resesten" till vänster. Förlagan till planschen över staden Troja finns $i$ Kungliga Biblioteket.

Stopp ett tag, säger väl vän av ordning, Troja i Småland - vem kan ha sådana idéer?!!

Jo, mannen bakom Smålands stolta forntid är Petter Rudebeck, som under slutet av 1600talet skrev sin stora historik över det gamla Småland. Petter Rudebecks i stort sett färdigredigerade manuskript omfattar runt 300 handskrivna foliosidor och bär det pampiga 
namnet: "Forna Rijdghiöta eller Smålendske Antiqviteter med dess Tillhörige

Kopparstycken och alle der hoos passerade Historier utur mörkret Upsökte igenfundne afritade och Sammanskrefne aff Petter Rudebeck Anno 1693". Vanligen kallas manuskriptet kort och gott för Smålendske Antiqviteter. Petter Rudebecks historia kom aldrig i tryck, men trots det har han varit känd och använd av senare tiders historieskribenter genom det flertal avskrifter som funnits. In på 1900-talet har hans manuskript visat sig värdefullt - inte minst för ballad- och visforskningen. I poesin i ballader och visor trodde sig nämligen Petter Rudebeck kunna finna en historisk sanning och därför tecknade han ned dem i sitt manuskript.

Petter Rudebeck arbetade dessutom ända in på det tidiga 1700-talet på ett komplement eller en tillökning till det första manuset, också detta på cirka 300 sidor. Sammantaget rör det sig alltså om drygt 600 sidor där Petter Rudebeck beskriver Smålands med intilliggande provinsers historia och antiqviteter. Av titeln som Rudebeck själv givit sitt verk framgår att han haft för avsikt att illustrera det med kopparstick, förmodligen är det de så kallade antiqviteterna som skall avbildas. Antiqviteter var nämligen det namn som under 1600-talet användes för det vi idag vanligen kallar forn-minnen eller fornlämningar.

Låt oss gå tillbaka till Petter Rudebecks manuskript och se vad mer han vet att berätta om det märkvärdiga och sällsamma Småland.

Jo - i Småland låg också det stora slagfältet Bråvalla hed, där oräkneliga drabbningar gått av stapeln. Särskilt tre stora slag är knutna till heden: göternas drabbning med Hunahären, Kung Rings slag mot den dansk/norske kungen Harald Hildetand samt det fältslag där kvinnohären eller den skäggalösa hären under ledning av hjältinnan Blända nedgjorde hela den danska armén.

Blända och hennes insatser är vid närmare betraktande rent otroliga! Det hela utspelade sig, enligt Petter Rudebeck, på den tiden då Kung Alle regerade i Småland. Denne konung och alla män som kunde bära vapen blev inbjudna att hjälpa kungen i Västergötland med fälttåget och kriget i Norge. När landskapet så var tömt på krigsmän passade de danske på att göra en inbrytning och överfalla Småland. Danskarna härjade vilt och grymt, allt var eländigt eftersom landet stod utan värn - då tog en ung kvinna Blända vid namn, manligt hjärta till sig och skickade ut budkavle runt Småland att alla kvinnor som var vapenföra skulle ta med sig vad de hade av mat och dryck och samlas på en bestämd mötesplats, som senare kom att kallas Quinneberga. Ett annat ställe där Blända och hennes skägglösa armé höll till kom att kallas Skäggalösa. De som hörsammmade Bländas kallelse var bara kvinnorna i de fem häraderna runt Växjö, men det blev en försvarlig armé ändå. Alla lyssnade till Bländas tal om försvar av hembygden i männens frånvaro och samtyckte till hennes plan, som genast sattes i verket.

Till danskarna skickades en bön om att de skulle sluta att härja landet och istället komma och möta kvinnorna som lovade att bli deras käre hustrur, eftersom de i männens frånvaro ändå var så gott som änkor. Därefter dukade kvinnorna upp ett dignande gästabudsbord på Bråvallahed. När Blända såg att Danskarna var i antågande så delade hon upp sin här i tre delar som alla gömde sig i skogarna runt heden. Själv ledde hon huvudhären och två andra generalinnor som hette Rambor och Sigrid ledde de två mindre avdelningarna.

Väl ankomna till den avtalade platsen fann danskarna blott ett uppdukat gästabudsbord, men de tänkte att kvinnorna nog blivit rädda. I sitt övermod gick de så långt att de hävdade att "Mat tjänar oss bättre än käringar". Därpå började de äta och fylla sig med öl, och snart bar det sig inte bättre än att var och en somnade där han satt och var - danskarna låg strödda över heden som slaktoxar. Plötsligt, på en given signal, bröt kvinnorna ut ur skogen med yxor, stakar och stänger i högsta hugg. Det blev ett så gruvligt manfall att inte en enda dansk levde över drabbningen.

Då kung Alle kom hem igen och fick höra om kvinnornas bragd belönade han dem på ett flertal sätt. Det främsta var att kvinnorna i de fem härader som värnat riket skulle ärva lika 
som manlig arvinge. Dessutom beviljades kvinnorna rätt att bära ett fälttecken eller en så kallad lista på sina högtidsdräkter, vid bröllop skulle kvinnorna äras med trummor och basuner i brudföljet precis som i ett krigståg. Dessutom fick de fem häraderna, som kom att kallas Värneland eller Värend eftersom de värnat riket i männens bortvaro, omfattande skattelättnader, men häraderna norr därom i Njudung fick en extra skatt för att kvinnorna där fegt sprungit undan. Denna skatt kallades därför springeskatten - i varje fall om vi vågar tro Petter Rudebecks Historia.

Ett flertal gravar och minnesmärken efter Bländas dust med danskarna och de två andra stora drabbningarna syntes klart och tydligt på slagfältet - i vart fall på 1690-talet. Petter Rudebeck själv råkade faktiskt bo just på den berömda Bråvalla hed, närmare bestämt på Huseby järnbruk några mil söder om Växjö, men hans väg till att bli småländsk brukspatron och historieskribent var allt annat än spikrak.

I förordet till Smålendske antiqviteter säger Rudebeck som svar till dem som kanske tror att han vill glorifiera sin fädernesbygd att "iag är en Westmanlänning och född i Biörskog sochn, och sålunda utom Pashion berättar det iag läsit, sett och hört om småländska saker". Att Rudebeck berättar om Småland utan passion vill jag låta vara osagt, men att han föddes i Västmanland stämmer helt och hållet. Fadern hette Paul Rudbeckius och var son till Johannes Rudbeckius, professor i Uppsala och blivande biskop i Västerås. En av Paul Rudbeckius bröder hette Olof, men är mer känd som Olaus Rudbeck - mannen bakom den så kallade Atlantikan, ett historieverk som sätter Sverige i världshistoriens mitt genom att hävda att det lyckliga och idealiska Atlantis som Platon talar om egentligen är Sverige, och att de flesta så kallade klassiska gudar och hjältar egentligen hade sin hemvist i Norden. Allt detta och mer därtill lyckades Olaus Rudbeck bevisa genom en salig blandning av klassiska historieverk, folklivsnotiser samt en snillrikhet och uppfinningsrikedom vid uttolkning av språk och ortnamn som forskningen tidigare inte sett maken till.

När Petter Rudbeckius, som han då hette, föddes den 30:e Juni 1660 var det alltså inte vilken släkt som helst som tog emot honom. Petters fader Paul var jurist och fram till 1662 verksam i Bergslagen, då han blev sekreterare vid Göta Hovrätt i Jönköping, i anslutning därtill gick flyttlasset till Småland. 1670, vid tio års ålder, skickades Petter till Växjö skola och gymnasium, och därifrån for han och några av hans bröder till Uppsala för att studera. Vid universitetet blev Petter kvar i fyra år och under den tiden, närmare bestämt 1675, blev hans fader Paul Rudbeckius adlad under namnet Rudebeck. 1678 lämnar Petter Rudebeck, som 18-åring, den akademiska banan för en militär karriär där han går från kornett via löjtnant till regementkvartermästare vid Kronobergs infanteri. 1689 begär han avsked från sin tjänst för annan militär verksamhet. Avskedet beviljas, men av hans andra planer blir inget av.

Vid 29 års ålder står Petter Rudebeck som yngre broder i en förhållandevis nyadlad familj, och som avdankad militär utan någon egentlig försörjning, dessutom är han ogift. Det är då, 1689, som han tillsammans med en av sina bröder drar igång driften vid det insomnade Huseby bruk söder om Växjö. Bruksdrift var inget nytt och ovant för familjen Rudebeck, redan tio år tidigare hade fadern Paul grundat ett nytt bruk i Väckelsångs socken, som bara ligger ett par mil från Huseby. Bröderna Rudebecks bruksrörelse var framgångsrik och de utökade senare med Lessebo järn- och pappersbruk. På Petter Rudebecks lott föll särskilt driften vid Huseby, och där blev han kvar till sin död 1710. Åren på Huseby fylldes med bruksdriften och arbetet på det stora verket Smålendske Antiqviteter, dessutom hann Petter Rudebeck med att gifta sig med en adelsföken som hette Anna Liwensten, paret fick tolv barn på 16 år, sex av de tolv barnen dog dock redan i späd ålder. 


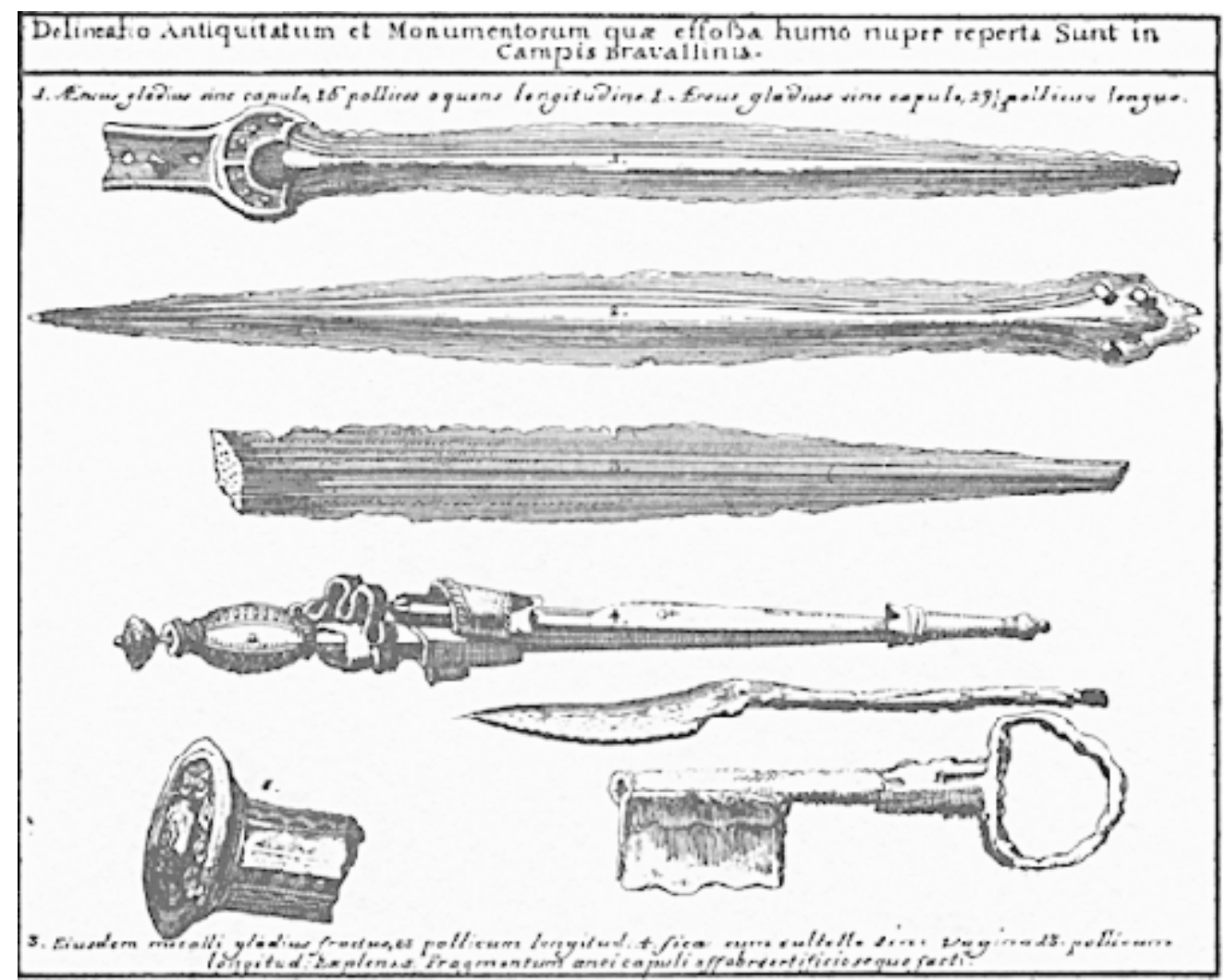

\section{Ill. 2. Jordfynd från Bråvallahed.}

Dessa saker hittades av en bonde som plöjde i närheten av Huseby. Petter Rudebeck tog hand om dem och överlämnade dem senare till Erik Dahlberg som lät avbilda dem i Sveciaverket och skänka dem till Antikvitetskollegiet. Nu förvaras de i Statens historiska museum. Förlagan till planschen finns $i$ Kungliga Biblioteket.

Låt oss återvända till det forna Småland med omnejd så som Petter Rudebeck såg landskapet under de sista åren av vår stormaktstid. Även om Blända kan sägas vara hans paradnummer, så finns det många andra fantastiska berättelser hos Rudebeck - eller vad sägs om: Den första göterkonungen Erik och hans stad Vitala; varifrån det som skulle bli Danmark koloniserades, eller den stora utvandringen från Angelstads socken till det land som efter de utvandrade anglerna kom att kallas England. En annan utvandring skedde från Långaryds socken och Lagaborgs slott - dessa utvandrare var de i hela Europa kända langobarderna som till sist slog sig ner i Italien. Langobard är ett gammalt Götiskt ord som betyder "de karlar som vilja slåss och rida länge". Namnet syftar på de som kämpade mest och red efter hunerna längst då dessa flydde krigsskådeplatsen i det stora hunahärsslaget på Bråvallahed. Dessa vildbasar slog sig sedan ner i socknen som efter dem kom att kallas Långaryd, en annan hop av dessa krigare bodde på och omkring Lagaborgs eller Lagabors slott.

Som framgår av utdragen ur Smålendske Antiqviteter har Petter Rudebeck tydligen velat skriva en Smålands historia illustrerad med märkliga fornlämningar från de trakter han beskriver - det låter väl som en hedervärd och någorlunda normal sysselsättning, men efter de inledande glimtarna kring Troja, Oden, Blända och Langobarderna inställer sig förmodligen frågan: "Var denne Petter Rudebeck en fullständigt galen man, slagen av vansinnesfantasier?"

Låt mig vänta lite med svaret på den frågan och istället säga något om Rudebecks förebilder. Som historieskribent hade Petter Rudebeck två viktiga inspiratörer. Den ene var den redan nämnde farbrodern Olaus Rudbeck som under Petters tid i Uppsala arbetade på sitt manus till Atlantikan och lät provtrycka delar av den första volymen under brorsonens vistande i lärdomsstaden. Olaus Rudbeck och Atlantikan kom att få ett betydande inflytande på Petter och hans Smålendske Antiqviteter. En annan, möjligen viktigare, 
påverkan och inspiration fick Rudebeck från Erik Dahlberg, en av den svenska stormaktstidens mer framståendende begåvningar. I hans levnadsbana ville Petter Rudebeck måhända se likheter med sin egen; Dahlberg föddes nämligen under små omständigheter, fick in en fot i det militära och gjorde en god karriär där, och adlades så småningom för sina insatser i rikets tjänst. Dessutom var han sysselsatt med att ge ut det som var avsett att bli en stor illustrerad historia om stormakten Sverige med dess fornlämningar och sevärdheter. Tyvärr blev det inget av texten, endast själva planschdelen förverkligades under namnet Svecia Antiqua et Hodierna. Med denne greve Dahlberg, som bland allt annat dessutom var riksråd och generalguvernör, upprätthöll Petter Rudebeck täta kontakter och bidrog flitigt med förslag till planscher som borde ingå i Sveciaverket, följaktligen är Småland det mest representerade landskapet i det färdiga planschverket - i varje fall då det gäller fornlämningar och andra märkvärdigheter.

På det tidiga 1690-talet kontaktar Erik Dahlberg Rudebeck för att få upplysningar från det gamla Småland. Av brevväxlingen från tiden framgår att Petter Rudebeck redan då har skrivit en del kring märkvärdigheter i Småland, så den tändande gnistan för Petter Rudebecks historiska författarskap kom inte från Erik Dahlberg. Vad är det då som har drivit honom till att teckna ned Smålands fantastiska, glömda historia? Man kan bara spekulera i om kärlek till hembygden, kärlek till det egna bruket eller den egna personen är tillräckligt för att förklara Rudebecks författande. Ville han kanske ge det i historieskrivningen försummade landskapet Småland en plats och en identitet?

Ytterligare en tänkbar förklaring till fenomenet Rudebeck är dårskapen som drivkraft. Var Petter Rudebeck vansinnig som hittade på och skrev sådana uppenbart horribla galenskaper? Svaret på frågan är egentligen enkelt - Nej! Petter Rudebeck var inte vansinnig. Däremot så är han och hans historia ett exempel på den yttersta, bräckliga grenen i en lång historieskrivnings-tradition som är en del av en föreställningsvärld eller en ideologi. Jag talar om den så kallade göticismen.

Den bärande tanken i denna mäktiga idévärld är att de i hela Europa kända goterna stammar från Sverige och är de samma som götarna, den uppdelning som finns i Europa mellan öst- och västgoter är gammal, den har de med sig från sitt fädernesland där det fortfarande finns östgötar och västgötar. I och med kopplingen goter - götar och vidare att folknamnet goter förknippas med en person som heter Gog gör man också Sverige till ett av de äldsta rikena på jorden. Gog är nämligen ingen mindre än Jafets son, och alltså barnbarn till gubben Noak själv.

Dessa spekulationer var inget unikt svenskt fenomen, de äldsta beläggen vi har för idéen om att goterna är från Nordlanden kommer ifrån Sydeuropa och koncentreras senare till spanska historieskrivare. I Norden och Sverige är spridda belägg för en göticistisk tolkning av historien kända från tidig medeltid. Som en viktig och tongivande kraft i Svensk historieskrivning och statsideologi visar sig Göticismen först på 1400-talet. Vid ett kyrkokoncilium i Basel år 1434 pågår rangstridigheter om hur delegaterna skall sitta vid förhandlingarna, de som är i luven på varandra är engelsmän och spanjorer som inte kan enas om vilken nation som är den främsta och bör sitta framför den andra. I stridens hetta drar spanjorerna till med argumentet att de är ättlingar till de vittberömda goterna. Yttrandet föranleder växjöbiskopen Nicolaus Ragvaldi att tala. Han var ett av sändebuden från unionskonungen Erik av Pommern i den Nordiska kyrkoprovinsen, och hans tal kom att slå alla med häpnad.

På konciliet gjorde Ragvaldi en utläggning om det land som var goternas ursprungliga hemvist, han gjorde också en exposé över alla de bedrifter och erövringar som dessa nästintill oövervinnerliga härskaror svarat för. Avslutningsvis yrkade Ragvaldi att konciliet borde ge en mycket förnäm plats åt sändebuden från Norden. De spanska sändebuden gjorde reflexionen att det var nog sant och väl det som sagts, men de stackars goter som blev kvar i sitt kalla hemland var ju de som inte hade någon som helst företagsamhet eller äventyrslust. Hur rangstriderna på konciliet löstes vet vi inte riktigt, men Nicolaus Ragvalidi fick i varje fall se sitt inlägg lämnas utan annan åtgärd än att han ombads lämna 
sin begäran skriftligen.

Göticismen får ordentligt fäste i Sverige under andra hälften av 1400-talet i och med de nationella strömningar som man brukar koppla till Karl Knutsson Bonde och hans olika regeringar. Under denna tid framträder också den svenske historieskrivaren Ericus Olai som en fullfjädrad företrädare för göticismen i sin könika om de götiska konungarna och deras bedrifter.

Höjdpunkten för göticismen är Johannes Magnus historieverk om Svea och Göta rikes konungar. Denna krönika utkommer första gången på 1540-talet, och då på latin. Den trycks i ett flertal upplagor och 1620 kommer en svensk översättning. Det sista uttrycket för en allvarligt menad göticism anses ibland vara Olaus Rudbecks Atlantika.

Efter denna korta skiss av göticismen kan man konstatera att där Petter Rudebecks företrädare nöjer sig med att knyta alla dessa stora krigsmän, deras bedrifter och ärofulla glans till Riket Sverige, går han steget längre och börjar knyta dem till särskilda orter inom landet - att sedan de flesta av dessa orter låg i Småland, ja till och med på Petter Rudebecks egna ägor och runt Huseby, det är en helt annan historia.

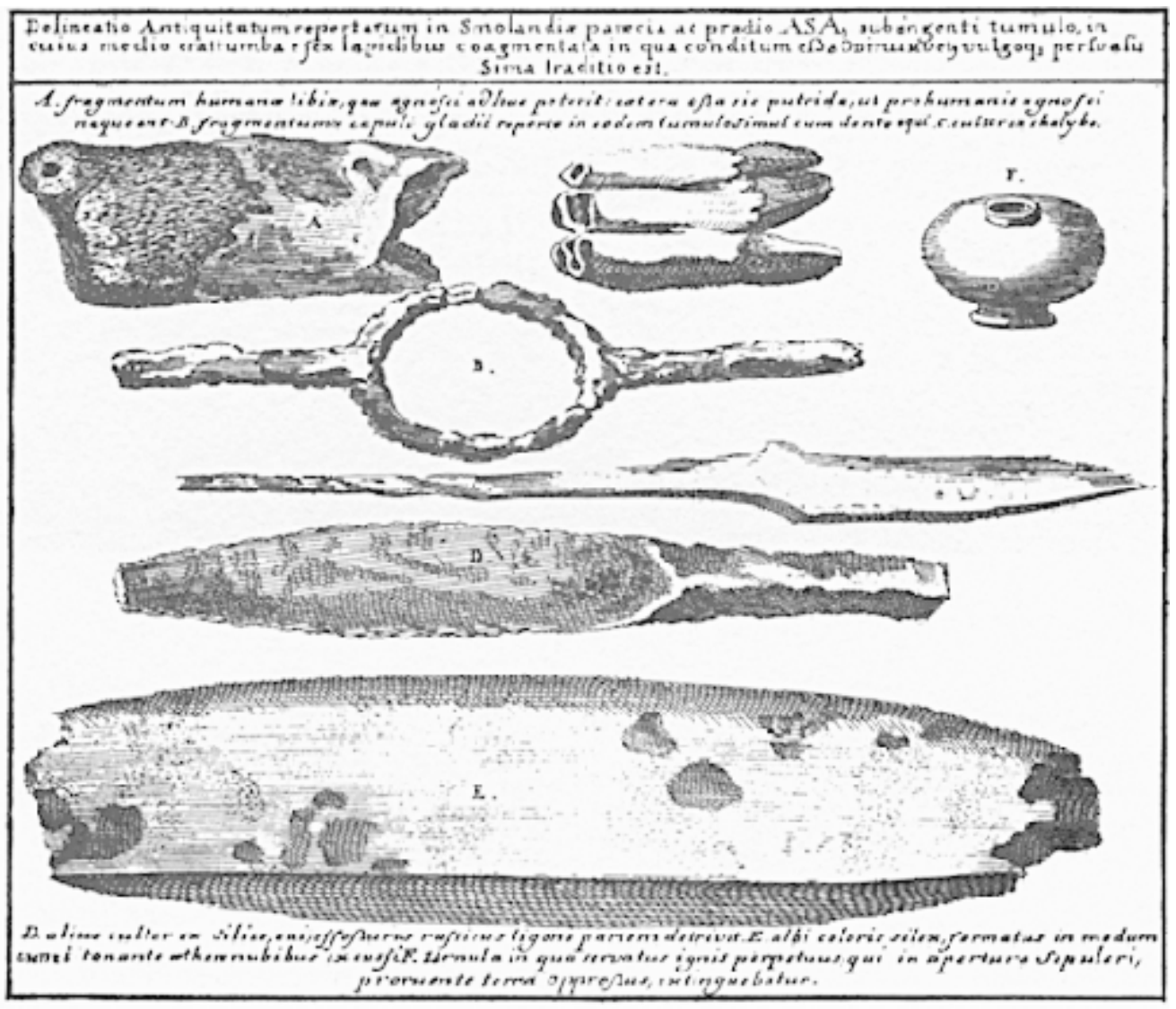

Ill. 3. Fornsaker från Asa socken.

Sticket visar de fynd som gjordes då "Odens grav" öppnades på 1660- eller 1670 -talet under ledning av Pär Ulfsparre på Asa gård eller "Asgård". I denna ort hade nämligen Oden bott på ålderdomen och då han dog blivit bränd och begraven där. I närheten kunde man också, i varje fall under slutet av 1600-talet, få se lämningarna av Sleipners stall kallat "Odens krubba" eller "Odens stallkrubba". Det är genom Petter Rudebecks försorg som Erik Dahlberg kommer i kontakt med dessa märkliga lämningar från vår forntid. Förlagan till planschen finns i Kungliga Biblioteket.

Den svenska stormaktsdrömmen dog 1709 i Poltava säger man ibland, året efter dog Petter Rudebeck utan att hans verk kommit i tryck, och därmed var väl det också dött - eller? Nej, inte direkt, Rudebecks Småländske Antiqviteter har visat sig vara segare än den svenska stormakten. Trots allt har Rudebeck och hans historia varit känd och använd av 
efterkommande historieskribenter tack vare de avskrifter som gjorts av originalmanuset. I en tid då trycktekniken inte var vad den är idag räckte det med ett antal avskrifter för att ett verk skulle få spridning och bli känt. Under hela 1700-talet med dess topografiska landskaps- och sockenbeskrivningar från Småland är Rudebecks ande påtagligt närvarande, på det det nygötiska och romantiskt forntidsälskande 1800-talet ser vi hur Rudebecks skrifter blir till en verklig guldgruva, man kan knappast tänka sig att Gunnar Olof HylténCavallius Wärend och Wirdarna skulle kunna ha kommit till utan Petter Rudebeck. HylténCavallius Värendsbeskrivning som sägs ha grundlagt etnologin i Sverige kom ut på 1860talet. Under 1900-talet har man kunnat se hur framför allt visforskare använt Petter Rudebecks balladuppteckningar, och hur man fortfarande tvistar om vad som är verkliga folksägner och folkvisor i Petter Rudebecks Antiqviteter, och vad som möjligen kan skildra en historisk sanning.

Petter själv, mannen bakom verket, framstår som alltmer svårbegriplig och svårfångad ju längre tiden går. Vem han var och vad han menade med sin historia kan vi bara spekulera i, hans grav i Skatelövs rivna gamla kyrka är borta, hans bruksherrgård på Huseby är ersatt med en yngre byggnad, endast delar av hans originalmanuskript är bevarat - och mig veterligen existerar det inte ens en avbildning eller ett porträtt av Petter Rudebeck. Men historieskribenten Petter Rudebeck och hans Smålendske Antiqviteter är, på gott och ont, i högsta grad levande - inte minst som identitetsskapande. Det händer inte alltför sällan att man kan få läsa en arg insändare i Smålandsposten med signaturen Blända - och då gäller det att passa sig!

\section{(Föredrag hållet i 'Värt att veta' P1 950504)}

